Unemployment, Disability and Life Expectancy in the United States: A Life Course Study

James N. Laditka, DA, PhD

Sarah B. Laditka, PhD*

James N. Laditka, DA, PhD, is Associate Professor, Department of Public Health Sciences, Associate Professor of Public Policy, University of North Carolina at Charlotte, 9201 University City Boulevard; Charlotte, NC 28223; phone: 704.687.8742; fax: 704.687.1644; Email: jladitka@uncc.edu.

Sarah B. Laditka, PhD, is Associate Professor, Department of Public Health Sciences, Associate Professor of Public Policy, University of North Carolina at Charlotte, 9201 University City Boulevard, Charlotte, NC 28223; phone: 704.687.5390; fax: 704.687.1644; Email: sladitka@uncc.edu.

*Corresponding author

Both authors participated in the conception and design of the study, the analysis of the data and interpretation of the results, drafting the manuscript, and final approval of the manuscript for submission.

Disclosure: The authors have no conflicts of interest.

Funding: The authors received no financial support for the research or authorship of this manuscript.

Portions of preliminary results of this study were presented at the Department of Public Health Sciences Seminar Series, Medical University of South Carolina, Charleston, South Carolina, on September 21, 2014, titled "Treats All 'Round: Using Multinomial Markov Modeling and Microsimulation to Address Missing Data in Longitudinal Analysis in a Study of Unemployment and Active Life Expectancy."

Portions of preliminary results of this study were presented as a peer reviewed poster at the annual meetings of the Gerontological Society of America, Washington, DC, November 5-9, 2014, titled, "Associations between Unemployment and Active Life Expectancy: Four Decades of Panel Survey Evidence."

The data used for this study are available from the Panel Study of Income Dynamics, http://simba.isr.umich.edu/data/data.aspx.

Word count: abstract: 250; text 3,991; references 51; tables 2

Key Words: Active life expectancy; African Americans; Disability; Health disparities; Panel data; Unemployment 


\section{Unemployment, Disability and Life Expectancy in the United States:}

A Life Course Study

Disclosure: The authors have no conflicts of interest.

Funding: The authors received no financial support for the research or authorship of this manuscript.

The data used for this study are available from the Panel Study of Income Dynamics, http://simba.isr.umich.edu/data/data.aspx.

Word count: abstract: 250; text 3,991; references 51; tables 2

Key Words: Active life expectancy; African Americans; Disability; Health disparities; Panel data; Unemployment 


\section{Abstract:}

Background: Unemployment may be associated with health through factors including stress, depression, unhealthy behaviors, reduced health care, and loss of social networks. Little is known about associations of total lifetime unemployment with disability and life expectancy. Hypothesis: People with high unemployment ( $\geq$ the median) will live shorter lives with more disability than those with less unemployment.

Methods: Data were nationally representative of African Americans and non-Hispanic whites, from the Panel Study of Income Dynamics (37 waves 1968-2011, n=7,970, mean work years=24.7). Seven waves $(1999-2011,58,268$ person-years $)$ measured disability in activities of daily living. We estimated monthly probabilities of disability and death associated with unemployment using multinomial logistic Markov models adjusted for age, sex, race/ethnicity, education, health status at baseline and throughout work life, and social support. We used the probabilities to create large populations with microsimulation, each individual having known monthly disability status, age 40 to death. We analyzed the populations to measure outcomes. Results: Respectively for African American and white women and African American and white men, life expectancies (with $95 \%$ confidence intervals) from age 40 with low unemployment were ages: 77.1 (75.0-78.3), 80.6 (78.4-81.4), 71.4 (69.6-72.5), and 76.9 (74.9-77.9). Corresponding high unemployment results were: 73.7 (71.7-75.0), 77.5 (75.1-78.0), 68.4 (66.8-69.0), and 73.7 (71.5-74.3). The percentage of life disabled from age 40 was greater with high unemployment for the same groups, by $23.9 \%, 21.0 \%, 21.3 \%$, and $21.1 \%$ (all $p<0.01$ ). Conclusions: High lifetime unemployment may be associated with a larger proportion of later life with disability and lower life expectancy. 
Introduction

Many Americans experience unemployment. The United States Department of Labor defines being unemployed as not having a job, having actively looked for work in the past month, and being currently available for work. ${ }^{1}$ At any time during the 2008-2013 recession more than twelve million Americans were unemployed, at least five million for six months or more. ${ }^{2}$ Even with economic recovery, 8.7 million are unemployed, nearly a third at least six months. ${ }^{2}$ Globalization, changing technology, contract labor, and outsourcing may increase unemployment. ${ }^{3}$ There is evidence that unemployment is associated with declining health. ${ }^{4-7}$ However, studies of associations between unemployment duration and health have been limited to small geographic areas, ${ }^{8-10}$ brief periods, ${ }^{11,12}$ or heart attack. ${ }^{13}$ Little is known about associations of unemployment with active life expectancy, a central public health indicator that measures life expectancy and the proportions of later life with and without disability. ${ }^{14-16} \mathrm{We}$ examined those associations.

\section{Pathways Linking Unemployment with Health}

Researchers often attribute poor health associated with unemployment to stress. ${ }^{4,5,8,17}$ Research has suggested associations between unemployment and arthritis, ${ }^{7}$ dementia, ${ }^{7}$ depression, ${ }^{5,11,18-21}$ heart attack, ${ }^{13}$ heart disease ${ }^{13,22}$ hypertension, ${ }^{23}$ obesity, ${ }^{24}$ stroke, ${ }^{12}$ high cortisol and inflammation, ${ }^{25,26}$ poorer self-rated health, ${ }^{7,22}$ and suicide. ${ }^{5}$ Arthritis, dementia, depression, heart disease, obesity, and stroke have been linked with higher risks of impairments in activities of daily living (ADLs). ${ }^{27}$ Results of two studies suggest that job loss may be associated with ADL impairment. ${ }^{11,28}$

Unemployment may reduce self-efficacy, leading to poorer decisions about health, behaviors, and medical care. ${ }^{29}$ Some people who lose their jobs may become less physically 
active, increase use of alcohol or tobacco, ${ }^{4,5,8,17,30,31}$ pay less attention to nutrition, ${ }^{8,24}$ or abuse drugs, ${ }^{24,31}$ although some research suggests that health behaviors may actually improve with unemployment. ${ }^{32}$ People who are unemployed may be less likely to control diabetes, heart disease, and lung conditions. ${ }^{33}$ Unemployment affects social networks, roles, and relationships. ${ }^{8,17}$ Social isolation and relationship stress are associated with diseases linked with disability. ${ }^{34}$ Unemployment can disrupt the sequence of life events such as establishing a career and retiring. ${ }^{21,35}$ Such disruptions have been associated with poorer health and increased mortality. ${ }^{21}$

A quantitative meta-analysis used 42 studies from throughout the world to examine the association of unemployment with mortality. ${ }^{32}$ Based on studies that adjusted for age and other covariates, unemployment was associated with a 78\% higher mortality risk for men, 37\% for women. ${ }^{32}$ Other studies have found $44 \%$ higher mortality following job loss from a plant closure ${ }^{36}$ and that mortality risk following job loss varied with macroeconomic conditions. ${ }^{9}$ Two studies examined such associations in the United States. One found 50\% to $100 \%$ higher mortality in the year after job loss among Pennsylvania workers with high seniority, with continuing risk even after 20 years. ${ }^{10}$ Another associated each $1 \%$ increase in county unemployment with a $6 \%$ increase in mortality for working age men. ${ }^{6}$

Many studies suggest that unemployment may follow disability, or that pre-existing health conditions or unhealthy behaviors increase the risks of both unemployment and later disability. ${ }^{32}$ Many of those studies are limited to cross-sectional data, providing limited information about which comes first, the risk factors or unemployment. ${ }^{32}$ However, the meta-analysis described above concluded that pre-existing behaviors and health conditions accounted for some of the observed association between unemployment and mortality, ${ }^{32}$ so it is 
essential for studies in this area to control for health status before the period when unemployment is measured. ${ }^{18}$ The meta-analysis also found that pathways following unemployment were more strongly associated with mortality risk than the factors that preceded unemployment. ${ }^{32}$

Unemployment and Health for African Americans and Whites

There is substantial evidence of disparities in health, disability, and life expectancy between African Americans and non-Hispanic whites (hereafter referred to as whites). ${ }^{25,37-43}$ If unemployment is differently associated with health for these groups, unemployment may be associated with those disparities. Hypotheses regarding unemployment and health for African Americans and whites include "double jeopardy," more health consequences for African Americans due to social and economic disparities, and "reverse double jeopardy," more negative health consequences for whites due to greater losses of income and job prestige. ${ }^{22}$ Limited empirical research has examined these hypotheses. ${ }^{22}$

\section{Study Contributions and Hypotheses}

We modelled the association of unemployment with the joint dynamics of disability and death, the active life expectancy analysis, using panel survey data that followed individuals for 43 years. We hypothesized that people with high lifetime unemployment would have shorter lives with more disability than those with less unemployment. We controlled for health prior to the period when we measured unemployment, and also during that period. We controlled for educational attainment, which is associated with risks of unemployment, disability, and death, ${ }^{12,20,22,38}$ and for social support from spouses or partners, which may moderate risks of disability and death. ${ }^{8,18,22,44}$

Limited evidence and conflicting theories about associations of unemployment with 
disability and life expectancy for African Americans and whites did not support a separate hypothesis regarding those associations. However, given the health disparities affecting African Americans and evidence that unemployment may be importantly associated with health, we believed it was useful to provide separate active life expectancy estimates for those groups. To further address the possibility that health problems or disability may precede unemployment, we also examined associations of participants' reports of health problems that made it difficult to work with later unemployment. We refer to that portion of the study as the work disability analysis. 
Methods

\section{Data Source and Sample}

We used data from the Panel Study of Income Dynamics (PSID), the longest-running household panel study in the world. ${ }^{45}$ The data were a nationally representative United States sample of African Americans and whites (n=7,970), who were 94.3\% of the American population when the PSID began collecting data in $1968 .^{46}$ The PSID interviewed participants every year from 1968 through 1997, and every two years since then.

\section{Measuring Disability and Death}

We identified ADL disability for the active life expectancy analysis from participants' reports in seven survey waves, 1999 through 2011, of "any difficulty...because of a health or physical problem" with bathing, eating, dressing, getting into or out of a bed or chair, walking, getting around outside, or getting to and using the toilet, each activity by themselves and without special equipment.

The work disability analysis used PSID data from 1968 through 2011 (37 survey waves). In most years, the PSID asked participants if they had a "physical or nervous condition" that limited the work they could do, and how much the condition limited work. We identified a level of work disability for each year: none, moderate ("somewhat" limited), or severe (limited "a lot" or could not work at all). In some years before 1980 participants were not re-asked the work disability questions unless they established or joined a new household. We estimated the models with data from years when the participant answered the work disability questions.

The PSID identified death dates using the National Death Index, compiled by the National Center for Health Statistics from state vital records. The Index records all deaths including participants lost to follow-up. There were 850 deaths, 1999-2011. 


\section{Measuring Unemployment}

In all survey waves, the PSID asked how long each participant was unemployed in the preceding year. Beginning with 1999, when the PSID conducted the survey every other year, interviewers asked separately about each of the two previous years. Consistent with the Department of Labor definition of unemployment, ${ }^{1}$ the PSID counted workers expecting to be recalled from layoff among the unemployed whether or not they engaged in a specific job-seeking activity. We examined all years in the labor force beginning with 1972 and summed the number of unemployed days across all years. We required participants to have at least five years in the labor force beginning with 1972, either employed or unemployed, to limit effects of limited labor market participation. We defined high unemployment as a total number of days equal to or greater than the median; all others had low unemployment.

\section{The Model Relating Unemployment to Disability and Death}

We estimated monthly probabilities of disability and death associated with unemployment using multinomial logistic Markov models. ${ }^{39-42,47-49}$ Each observation in the analytic data represented a transition, from not disabled to disabled, not disabled to dead, disabled to not disabled, disabled to dead, remaining not disabled, or remaining disabled. The model estimated four parameters for each covariate, representing the first four of those transitions. Remaining not disabled and remaining disabled were reference categories. In addition to the unemployment measure and the controls described in the passages that follow, the model included age in years, and age-squared.

\section{Controlling for Health Status}

We used the first four years of employment information for each participant to measure health in the period before we measured unemployment. For most participants the first four 
years were 1968-1971. This baseline health measure was the average annual number of work days lost due to illness. A separate measure controlled for the average annual number of such illness days across all later years in the labor force. Each of these variables was represented in the model by a categorical measure with three levels defined by tertiles.

Controlling for Education, Sex, Race/Ethnicity, and Social Support

The control for education measured: less than 8 years, completion of grade 8 , completion of grades 9 through 12 without a high school diploma, high school graduation, some education after high school, or at least a 4-year college degree. We first estimated a model with a separate dummy variable representing each of those levels. Results indicated linear risk relationships across education levels for all transition types (all $\mathrm{R}^{2}>0.92$ ). We therefore estimated a final model with education as a categorical variable representing those six levels. We controlled for sex and race/ethnicity. A dummy variable indicated whether the participant had a spouse or partner in each year that we measured disability, 1999-2011.

\section{Microsimulation}

We used microsimulation to create a complete monthly history of disability status for each individual in the population, age 40 through death, with a separate microsimulation for each population defined by sex and race/ethnicity. ${ }^{40,47-49}$ Based on the monthly probabilities of disability and death combined with a random number draw for each simulated month, the individual went from being nondisabled or disabled in the previous month to nondisabled, disabled, or dead. We used the weighted PSID to estimate the proportion of each population with each education level. When simulating each population proportion, we used the probabilities associated with the educational attainment of that proportion. The analogous approach controlled for baseline and work-life illness days, and social support. Each simulated 
population represented one million individuals. We analyzed the simulated populations to measure the outcomes. Active life expectancy measures the proportions of remaining life with and without disability; consistent with many studies, we report the proportion with disability. ${ }^{39-}$ 42,47-49

Estimating Variation in the Microsimulation Results

We used bootstrapping to estimate variation in the microsimulation results, accounting for parameter uncertainty and Monte Carlo variation, repeating the microsimulation for each population 100 times. Each repetition randomly selected the value for each parameter from its 95\% confidence interval (CI). We report the mean from the repetitions. The reported CIs are the $2.5^{\text {th }}$ and $97.5^{\text {th }}$ percentiles of those results. The analysis used SAS IML (Cary, North Carolina). This research was approved by the Institutional Review Board at [blinded for review]. Sensitivity Analyses

We used total lifetime unemployment as the principal exposure measure because we judged that it best represented the total lifetime unemployment "dose." We analyzed the sensitivity of the results to that choice by estimating models using average annual unemployment. In the principal analysis we defined high unemployment based on the median total unemployed days for all participants; a sensitivity analysis used the median total unemployed days within each group defined by sex and race/ethnicity. We also examined the association of missing data with the variables in the model using discrete-time hazard analysis, adjusting standard errors for the repeated measures for each individual.

Examining the Association of Work Disability with Later Unemployment

We estimated associations between work disability and later unemployment using discrete-time hazard analysis with PSID data from 1968-2011. We examined the association 
between an individual reporting a moderate work disability in a given year and any unemployment the next year, controlling for age, sex, and race/ethnicity, adjusting standard errors for repeated measures. An analogous model studied the association of severe work disability with unemployment in the following year. Two final analyses examined associations of moderate or severe work disability with high lifetime unemployment. 
Results

Descriptive Results

The analytic data used for the active life expectancy analysis had 28,974 records, representing 58,268 person-years for the outcome measurement period beginning with 1999 . In weighted nationally representative results that accounted for the survey design, the mean age when we began measuring disability in 1999 was 53.4 years (standard error, SE, 0.3). Women were $54.7 \%$ of the weighted sample (SE <0.1). The PSID over-sampled African Americans, who were $31.9 \%$ of the unweighted sample, $12.4 \%$ when weighted (SE 1.3). People with low and high unemployment both averaged 24.7 (SE 0.4) total years employed or unemployed. Average annual unemployed days were 46.3 (SE 11.7) for high unemployment, 18.3 (SE 2.3) for low unemployment. Table 1 shows those results separately for African American and white women and men. The average annual number of unemployed days varied among the groups. For example, among those with high unemployment African American men averaged 73.0 (SE 54.3) days, compared with 38.8 (SE 15.4) for white men.

[Table 1]

\section{Active Life Expectancy Results}

At least one of the four parameters for each covariate in the multinomial logistic Markov model was statistically significant $(p<0.001)$. For example, of the four parameters associated with the individual's being married or having a partner at the time of each disability measurement (1999-2011), three were statistically significant. Those who were married or had a partner, compared to others, had $16 \%$ lower odds of becoming disabled (odds ratio, OR 0.84, 95\% confidence interval, CI 0.74-0.95), $25 \%$ lower odds of dying while not disabled (OR 0.75, CI 0.57-0.99), and 28\% greater odds of recovering from disability (OR 1.28, CI 1.11-1.49). The 
fourth parameter was consistent with lower risk of dying while disabled for those who were married or had a partner, but not statistically significant (OR 0.88, CI 0.71-1.10) (parameter results not shown in a table).

The principal results appear in Table 2, which presents life expectancy and disability measures for African American and white women and men with low unemployment (left hand panel) and high unemployment (right hand panel). Respectively for African American and white women and African American and white men, life expectancies (with 95\% confidence intervals) from age 40 with low unemployment were ages: 77.1 (75.0-78.3), 80.6 (78.4-81.4), 71.4 (69.672.5), and 76.9 (74.9-77.9). Corresponding results with high unemployment were: 73.7 (71.775.0), 77.5 (75.1-78.0), 68.4 (66.8-69.0), and 73.7 (71.5-74.3). All life expectancy comparisons between those with high and low unemployment were statistically significant at age 40, as were those for African American women and white women and men at age 55, indicated by confidence intervals that did not overlap.

Among African American women, the percentage of life disabled from age 40 was $14.0 \%$ (CI 12.7-14.5) with high unemployment, $11.3 \%$ (CI 10.2-11.9) with low unemployment, a 23.9\% greater proportion of remaining life disabled for those with high unemployment (percentage difference not shown in the table). High unemployment was similarly associated with a greater percentage of remaining life disabled for African American men (a 21.3\% greater proportion of remaining life disabled), white women $(21.0 \%)$ and white men $(21.1 \%)$ (all $\mathrm{p}<0.01)$. For all groups studied, the results from age 70 were consistent with more disability and shorter lives for those with high unemployment, although not statistically significant.

[Table 2]

Results of the Sensitivity Analyses 
Results of the analysis that measured unemployment as the average annual number of days were similar to the results just presented. Results of the analysis that separately calculated median total unemployed days for each group defined by sex and race/ethnicity were also similar to the results presented. Regarding missing data, of all opportunities for participants to respond to surveys between their first and last disability measurements, $2.4 \%$ had missing data. In results of the discrete-time hazard analysis that examined the association of the variables in the model with a dummy variable that indicated missing data, none of the covariates were statistically significant, suggesting that data were missing at random.

Associations of Work Disability with Later Unemployment

The analysis of the association of work disability with later unemployment examined 121,923 analytic observations, an average of 15.3 years of working life for each participant (results not shown in tables). Of all individuals: 15.3\% (CI 13.1-17.5) reported severe work disability at least once; $2.1 \%$ (CI 1.6-2.7) reported severe work disability at least once and were unemployed in the following year; $36.0 \%$ (CI 33.2- 38.9) reported moderate work disability at least once; $5.0 \%$ (CI 4.2-5.9) reported moderate work disability at least once and were unemployed in the following year. Compared to participants who were in the work force and did not report a work disability, individuals who reported moderate work disability had a higher unemployment risk the following year, with hazard ratio 1.02 (CI 1.01-1.03). There was no evidence linking severe work disability with unemployment $(p=0.867)$. Results of the analyses of the associations of moderate and severe work disability with high lifetime unemployment were not statistically significant. 


\section{Discussion}

Consistent with our hypothesis, African American and white women and men with high unemployment had shorter lives than those with low unemployment. Also consistent with our hypothesis, all groups with high unemployment were disabled through more of later life than those with low unemployment. There were no meaningful differences between African Americans and whites in the association of unemployment with either life expectancy or the proportion of remaining life with disability.

We found evidence that having a moderate work disability may be associated with later unemployment. Although the increased risk of being unemployed in the year following a report of moderate work disability was only $2 \%$, the cumulative work-life results of that greater annual risk could be considerable if an individual had a moderate work disability for many years. If unemployment experiences increase the likelihood of later unemployment, even a modest increase in the risk of becoming unemployed due to a work disability in a given year could meaningfully affect lifetime risks of unemployment, disability, and death. We found no evidence that those who reported severe work disabilities had a higher risk of becoming unemployed. That result may be due in part to withdrawal from the labor market by those who became severely work disabled, many of whom reported that they could not work at all. There was no evidence that having a work disability in a given year was associated with high lifetime unemployment.

There is no closely related research to which we can compare the results as few studies have had national focus, followed individuals' labor market status across many years, or measured outcomes repeatedly for more than a decade. Previous studies have not examined the associations of unemployment with the joint dynamics of disability and mortality. The life 
expectancy results were generally consistent with studies of job loss and mortality. ${ }^{6,9,10,32}$ The greater proportion of remaining life with disability for people with high unemployment was consistent with studies that have associated job loss with ADL disability, ${ }^{11,28}$ fair or poor self-rated health, ${ }^{7,22}$ and heart conditions. ${ }^{7,13}$

Several factors should be considered when interpreting the results. There are many ways to measure unemployment such as the number of spells, their average duration, and their placement in the life course. Alternative measures might produce different results. The analysis did not include the reason for unemployment, such as whether voluntary or involuntary, or due to declining health. ${ }^{18}$ Such reasons may be associated with the risks of declining health during or after periods of unemployment.

The results do not necessarily indicate that unemployment increases disability and mortality. The results may be due to unmeasured factors associated with both unemployment and the outcomes we measured. Such factors could include unmeasured health conditions or behaviors before unemployment, socioeconomic differences not captured by education, working in industries with both declining employment and high occupational health risks, or employment in occupations with both high unemployment risks and poor health care coverage. To the degree that such factors exist and are not accounted for by our model, the results may over-estimate the association of unemployment with later disability and life expectancy.

The multinomial logistic Markov model and the microsimulations adjusted for being married or having a partner in each year when we measured disability and mortality. Results suggested that having that social support reduced the risk of becoming disabled and the risk of dying, while increasing the likelihood of recovering from disability. A limitation of the analysis is that the model could not control for social support during years when the individual 
experienced unemployment.

It would have been desirable to provide separate estimates for American Indians, Asians, Hispanics and other demographic groups. The PSID has included a substantial sample of Hispanics since 1990. However, those data do not provide the lifetime unemployment history required for our analysis. Other groups are not represented by large enough PSID samples to support analyses using our methods.

We described the data as "lifetime" histories of employment and unemployment. Although the information about work represented almost 25 years for the average participant, Americans typically work more years than we measured. We have no reason to believe that the years we measured might not be representative of all labor market years throughout participants' lives.

Although functional limitations contribute to disability, social arrangements contribute, as well. Functional limitations can be accommodated by social arrangements to varying degrees, depending on the specific limitations and the social arrangements. Thus, the biopsychosocial model of disability, the basis for the World Health Organization's International Classification of Functioning, Disability and Health (commonly known as the ICF), stresses that both contextual factors and personal factors shape disability ${ }^{50}$ Contextual factors include availability and qualities of health care and rehabilitation services, the built environment, climate, educational opportunities, legal and social structures, social attitudes, terrain, and workplace policies and cultures. Personal factors not controlled for in our models include depression and stress, health behaviors and coping styles, self-efficacy, social networks, employment duration preceding unemployment, occupational prestige, the significance of work and career for the individual, and social background. Any of these factors may influence the individual's experience of 
unemployment or disability. The analytic approach that we used generally requires parsimonious models, so the number of controls for such factors was limited. The controls for educational attainment, illness days, and social support are likely to have accounted for some of the variation associated with such factors.

A related consideration is that the disability measure was limited to a summary indicator, whether the participant reported difficulty with one or more ADLs. It would be useful to examine associations of unemployment with individual ADLs and with levels of ADL impairment, as well as other disability measures. Useful next steps might also examine how macroeconomic conditions at the time of unemployment affect the associations we studied. ${ }^{6}$ Unemployment insurance and related social programs vary among states and over time. It would be useful to examine associations of unemployment with active life expectancy in the context of that variation.

Estimates of health conditions from the PSID are consistent with those from the Health and Retirement Study and the National Health Interview Survey; the PSID's item-specific response rate is over $99 \% .{ }^{51}$ Modeling the risks of disability and death beginning at age 40 was another strength of the analysis. That is considerably younger than the baseline age used in most active life expectancy research, typically 55,65 , or 70 , often determined by data availability. It is likely that this feature of the analysis limited bias associated with younger disability onset and lower life expectancy for some demographic groups, including individuals with high total lifetime unemployment and African Americans. ${ }^{14,25,26,37-40}$

The results of this study suggest that a history of high unemployment may be associated with lower life expectancy and a greater proportion of older life with disability for African American and white women and men. 



\section{Acknowledgments}

The collection of data used in this study was partly supported by the National Institutes of Health under grant number R01 HD069609, and the National Science Foundation under award number 1157698. We thank two anonymous reviewers for useful suggestions about this research. 


\section{References}

1. Bureau of Labor Statistics. How the government measures unemployment. United States Department of Labor. [cited 2015 June 24]. Available from: http://www.bls.gov/cps/cps_htgm.htm\#unemployed.

2. Bureau of Labor Statistics. Unemployment in May 2015. [cited 2015 June 13]. Available from: http://www.bls.gov/news.release/pdf/empsit.pdf.

3. Weil D. The fissured workplace: why work became so bad for so many and what can be done to improve it. Cambridge, MA: Harvard University Press; 2014.

4. Burgard SA, Ailshire JA, Kalousova L. The great recession and health: people, populations, and disparities. Ann Am Aca Pol Soc Sci. 2013;650:194-213.

5. Dooley D, Fielding J, Levi L. Health and unemployment. Annu Rev Public Health 1996;17:449-65.

6. Halliday TJ. Unemployment and mortality: evidence from the PSID. Soc Sci Med. 2014; 113:15-22.

7. Strully KW. Job loss and health in the U.S. labor market. Demography 2009; 46(2):221-46.

8. Kalousova L, Burgard SA. Unemployment, measured and perceived decline of economic resources: contrasting three measures of recessionary hardships and their implications for adopting negative health behaviors. Soc Sci Med. 2014; 106:28-34.

9. Martikainen P, Mäki N, Jäntti, M. The effects of unemployment on mortality following workplace downsizing and workplace closure: a register-based follow-up study of Finnish men and women during economic boom and recession. Am J Epidemiol. 2007; 165:1070-75.

10. Sullivan D, von Wachter Till. Job displacement and mortality: an analysis using 
administrative data. Q J Econ. 2009; 124(3):1265-1306.

11. Gallo WT, Bradley EH, Siegel M, Kasl SV. Health effects of involuntary job loss among older workers: findings from the Health and Retirement Study. J Gerontol B Soc Sci. 2000; 55B: S131-40.

12. Gallo WT, Bradley EH, Falba TA, et al. Involuntary job loss as a risk factor for subsequent myocardial infarction and stroke: findings from the Health and Retirement Study. Am J Ind Med. 2004; 45: 408-16.

13. Dupre ME, George LK, Liu G, Peterson ED. The cumulative effect of unemployment on risks for acute myocardial infarction. Arch Intern Med. 2012; 172(22): 1731-7.

14. Laditka SB, Laditka JN. Active life expectancy: a central measure of population health. In: Uhlenberg P, ed. International handbook of the demography of aging. Netherlands: Springer-Verlag; 2009: 543-65.

15. Robine JM, Jagger C, Mathers C, Crimmins EM, Suzman R, eds. Determining health expectancies. Baffins Lane, Chichester, Sussex, UK: John Wiley \& Sons; 2003.

16. SaitoY, Robine JM, Crimmins EM. The methods and materials of health expectancy. Statistical J IAOS. 2014;30: 209-23.

17. Berchick ER, Gallo WT, Maralani V, Kasl SV. Inequality and the association between involuntary job loss and depressive symptoms. Soc Sci Med. 2012; 75:1891-4.

18. Burgard SA, Brand JE, House JS. Toward a better estimation of the effect of job loss on health. J Health Soc Behav. 2007; 48(4): 369-84.

19. Mandal B, Ayyagari P, Gallo WT. Job loss and depression: the role of subjective expectations. Soc Sci Med. 2011; 72: 576-83.

20. Mandal B, Roe B. Job loss, retirement and mental health of older Americans. J Ment Health 
Policy Econ. 2008; 11: 167-76.

21. Price RH, Choi JN, Vinokur AD. Links in the chain of adversity following job loss: how financial strain and loss of personal control lead to depression, impaired functioning, and impaired health. J Occup Health Psychol. 2002; 7: 302-12.

22. Strully K. Racial-ethnic disparities in health and the labor market: losing and leaving jobs. Soc Sci Med. 2009; 69: 768-76.

23. Levenstein S, Smith MW, Kaplan GA. Psychosocial predictors of hypertension in men and women. Arch Intern Med. 2001; 161(10): 1341-6.

24. Deb P, Gallo WT, Ayyagari P, Fletcher JM, Sindelar JL. The effect of job loss on overweight and drinking. J Health Econ. 2011; 30: 317-27.

25. Levine ME, Crimmins EM. Evidence of accelerated aging among African Americans and its implications for mortality. Soc Sci Med. 2014; 118: 27-32.

26. Seemam T, Merkin SS, Crimmins E, Koretz B, Charette S, Karlamangla A. Education, income and ethnic differences in cumulative biological risk profiles in a national sample of US adults: NHANES III (1988-1994). Soc Sci Med. 2008; 66:72-87.

27. Martin LG, Freedman VA, Schoeni RF, Andreski PM. Trends in disability and related chronic conditions among people ages fifty to sixty-four. Health Aff. 2010; 29(4):725-31.

28. Gallo WT, Brand JE, Teng H-M, Leo-Summers L, Byers AL. Differential impact of involuntary job loss on physical disability among older workers. Res Aging 2009; 31(3): $345-60$.

29. Baroletti S, Dell'Orfano H. Medication adherence in cardiovascular disease. Circulation 2010; 121(12): 1455-8.

30. Gallo WT, Bradley EH, Dubin JA, et al. The persistence of depressive symptoms in older 
workers who experience involuntary job loss: results from the Health and Retirement Study. J Gerontol B Soc Sci. 2006; 61B(4): S221-8.

31. Henkel D. Unemployment and substance use: a review of the literature (1990-2010). Curr Drug Abuse Rev. 2011; 4: 4-27.

32. Roelfs DJ, Shor E, Davidson KW, Schwartz, JE. Losing life and livelihood: a systematic review and meta-analysis. Soc Sci Med. 2011; 72: 840-54.

33. Burgdorf F, Sundmacher L. Potentially avoidable hospital admissions in Germany: an analysis of factors influencing rates of ambulatory care sensitive hospitalizations. Dtsch Ärztebl Int. 2014; 111(13): 215-23.

34. Umberson D, Montez JK. Social relationships and health: a flashpoint for health policy. J Health Soc Behav. 2010; 51(1): S54-66.

35. Elder GH Jr. The life course as developmental theory. Child Dev. 1998; 69: 1-12.

36. Eliason M, Storrie D. Does job loss shorten life? J Hum Resour. 2009; 44(2): 277-302.

37. Hayward MD, Heron M. Racial inequity in active life among adult Americans. Demography 1999; 36:77-91.

38. Olshansky SJ, Antonucci T, Berkman L, et al. Differences in life expectancy due to race and educational differences are widening and many may not catch up. Health Aff. 2012; 31(8):1803-13.

39. Laditka JN, Laditka SB. Stroke and active life expectancy in the United States, 1999-2009. Disabil Health J. 2014; 7:472-7.

40. Laditka SB, Laditka JN. More education may limit disability and extend life for people with cognitive impairment. Am J Alzheimer's Dis Other Demen. 2014; 29(5): 436-47.

41. Laditka JN, Laditka SB, Olatosi B, Elder KT. The health tradeoff of rural residence for 
impaired older adults: longer life, more impairment. J Rural Health 2007; 23(2): 124-32.

42. Laditka SB, Laditka JN. Active life expectancy of Americans with diabetes: risks of heart disease, obesity, and inactivity. Diabetes Res Clin Prac. 2015; 107(1):37-45.

43. Sautter JM, Thomas PA, Dupre ME, George LK. Socioeconomic status and the black-white mortality crossover. AJPH 2012; 102:1566-71.

44. Laditka JN, Laditka SB. Increased hospitalization risk for recently widowed older women and the protective effects of social contacts. J Women Aging 2003; 15(2/3): 7-28.

45. Hill M. The panel study of income dynamics: a user's guide. Newbury CA: Sage Publications, Inc; 1992.

46. Gibson C, Jung K. Historical census statistics on population totals by race, 1790 to 1990 , and by Hispanic origin, 1970 to 1990, for large cities and other urban places in the United Statue. Population Division working paper no. 76. Washington DC: U.S. Census Bureau, 2005. [cited 2015 June 14]. Available from: http://www.census.gov/population/www/documentation/twps0076/twps0076.pdf.

47. Laditka SB. Modeling lifetime nursing home use under assumptions of better health. J Gerontol B Soc Sci. 1998; 53B(4): S177-87.

48. Laditka SB, Wolf DA. New methods for analyzing active life expectancy. J Aging Health 1998; 10: 214-41.

49. Laditka JN, Laditka SB. Associations of multiple chronic health conditions with active life expectancy in the United States. Disabil Rehabil 2015; epub ahead of print, May 4, 2015.

50. World Health Organization. Towards a common language for functioning, disability and health: ICF. [cited 2015 June 18]. Available from: http://www.who.int/classifications/icf/en/. 
51. Andreski P, McGonagle K, Schoeni R. An analysis of the quality of the health data in the Panel Study of Income Dynamics. Survey Research Center, Institute for Social Research University of Michigan. Technical Series Paper \#09-02; 2009. 
Table 1. Unemployment and active life expectancy, characteristics of the sample ${ }^{\text {a }}$

\begin{tabular}{|c|c|c|c|c|}
\hline & \multicolumn{2}{|c|}{ Women } & \multicolumn{2}{|c|}{ Men } \\
\hline & $\begin{array}{c}\text { African } \\
\text { American }\end{array}$ & White & $\begin{array}{c}\text { African } \\
\text { American }\end{array}$ & White \\
\hline Sample size, unweighted & 1,531 & 2,755 & 1,013 & 2,671 \\
\hline Sample distribution, weighted \% (SE) & $7.45(0.78)$ & $44.7(0.64)$ & $4.96(0.51)$ & $42.9(0.80)$ \\
\hline Annual work weeks lost to illness, 1968-1971, WM (SE) & $0.80(0.07)$ & $0.75(0.04)$ & $0.77(0.07)$ & $0.78(0.05)$ \\
\hline \multicolumn{5}{|l|}{ Employment measurement period $(1972-2011)$} \\
\hline Measured years of work or unemployment, WM (SE) & $21.43(0.70)$ & $23.87(0.44)$ & $23.35(1.32)$ & $27.25(0.42)$ \\
\hline Annual unemployed days, low unemployment ,WM (SE) & $20.46(5.52)$ & $17.34(4.96)$ & $22.42(7.49)$ & $16.00(3.52)$ \\
\hline Annual unemployed days, high unemployment WM (SE) & $56.05(19.66)$ & $32.64(16.11)$ & $73.02(54.28)$ & $38.82(15.36)$ \\
\hline Annual work weeks lost to illness, 1972+ WM (SE) & $1.32(0.11)$ & $0.93(0.04)$ & $1.15(0.11)$ & $0.93(0.05)$ \\
\hline \multicolumn{5}{|l|}{ Disability outcome period, 1999 - 2011} \\
\hline Age, 1999 or later entry, WM (SE) & $51.28(0.46)$ & $55.17(0.50)$ & $51.82(0.57)$ & $53.57(0.32)$ \\
\hline Educational attainment, years, WM (SE) & $12.7(0.17)$ & $13.4(0.16)$ & $11.9(0.19)$ & $13.5(0.18)$ \\
\hline Married, 1999 or later entry, weighted \% $(\mathrm{SE})^{\mathrm{b}}$ & $45.37(2.14)$ & $75.45(1.60)$ & $68.36(2.90)$ & $84.30(1.49)$ \\
\hline Age at death, WM (SE) & $72.2(2.64)$ & $79.6(1.12)$ & $67.8(2.05)$ & $76.2(1.61)$ \\
\hline Disability status transitions, mean per person & 3.5 & 3.8 & 3.3 & 3.7 \\
\hline Deaths, unweighted & 145 & 292 & 112 & 301 \\
\hline Measured disability status transitions & 5,314 & 10,488 & 3,295 & 9,877 \\
\hline Person years of measured disability status & 10,741 & 21,061 & 6,650 & 19,816 \\
\hline
\end{tabular}

${ }^{a}$ Data source: Panel Study of Income Dynamics, 1968-2011, n=7,970; WM=Weighted Mean; SE=Standard Error.

${ }^{\mathrm{b}}$ Later entrants for the disability outcome measurements are those reaching age 40 after 1999; results for marital status for 1999 or the first year of later entry; marital status was updated for modeling with each survey wave, 1999-2011. 
Table 2. Association of unemployment with life expectancy and the percentage of life disabled from ages 40,55 , and $70^{\mathrm{a}}$

NCHS TLE Low Unemployment High Unemployment

Women, from age:

$\begin{array}{lllllllllll}40 & 77.4 & 79.8 & 77.1 & (75.0-78.3) & 11.3 & (10.2-11.9) & 73.7 & (71.7-75.0)^{*} & 14.0 & (12.7-14.5)^{*} \\ 55 & 79.7 & 81.8 & 81.9 & (80.4-82.9) & 14.2 & (12.4-15.1) & 79.4 & (77.7-80.4)^{*} & 17.7 & (15.6-20.4)^{*} \\ 70 & 84.0 & 85.7 & 88.0 & (86.7-88.5) & 16.2 & (13.7-17.4) & 86.7 & (85.2-86.9) & 19.4 & (17.1-20.4)\end{array}$

Men, from age:

$\begin{array}{lllllllllll}40 & 71.9 & 74.9 & 71.4 & (69.6-72.5) & 8.9 & (8.0-9.3) & 68.4 & (66.8-69.0)^{*} & 10.8 & (9.8-11.4)^{*} \\ 55 & 75.4 & 77.5 & 75.5 & (73.9-76.1) & 10.8 & (9.2-11.6) & 73.1 & (71.4-73.8)^{*} & 13.3 & (11.8-13.9)^{*} \\ 70 & 81.6 & 82.8 & 81.2 & (79.7-81.7) & 17.3 & (14.7-18.9) & 79.7 & (78.1-80.0) & 21.1 & (18.1-22.5)\end{array}$

White, non-Hispanic

Women, from age:

\begin{tabular}{lllllllllll}
40 & 81.3 & 82.5 & 80.6 & $(78.4-81.4)$ & 10.0 & $(8.7-10.6)$ & 77.5 & $(75.1-78.0)^{*}$ & 12.1 & $(10.7-12.5)^{*}$ \\
55 & 82.5 & 83.8 & 82.5 & $(80.3-83.4)$ & 13.0 & $(10.9-13.7)$ & 79.8 & $(77.9-80.2)^{*}$ & 15.6 & $(13.4-16.3)$ \\
70 & 85.5 & 86.4 & 86.0 & $(83.8-86.6)$ & 20.1 & $(16.8-21.3)$ & 84.0 & $(81.9-84.5)$ & 24.2 & $(20.6-25.4)$ \\
& & & & & & & & & & \\
& & & & & & & & \\
40 & 76.9 & 78.6 & 76.9 & $(74.9-77.9)$ & 7.1 & $(6.0-7.6)$ & 73.7 & $(71.5-74.3)^{*}$ & 8.6 & $(7.7-9.2)^{*}$ \\
55 & 78.8 & 80.5 & 79.1 & $(77.4-79.7)$ & 9.5 & $(7.8-10.1)$ & 76.5 & $(74.5-76.9)^{*}$ & 11.6 & $(9.8-12.4)$ \\
70 & 82.9 & 84.2 & 83.5 & $(81.9-83.8)$ & 15.4 & $(12.9-16.5)$ & 81.5 & $(79.9-82.0)$ & 18.9 & $(15.6-20.4)$ \\
\hline
\end{tabular}

${ }^{\mathrm{a} D a t a}$ source: Panel Study of Income Dynamics, 1968-2011, n=7,970, 58,268 person-years. Results of multinomial logistic Markov models and dynamic microsimulation, adjusted for age, age-squared, sex, race/ethnicity, 6 levels of education, average annual work days lost due to illness in the 4 years preceding the first measured year of work or unemployment, average annual work days lost due to illness in remaining working life, and marital status in each year when disability was measured; high unemployment=lifetime unemployment $\geq$ the median, all others=low unemployment; NCHS=National Center for Health Statistics estimates (2010 are non-Hispanic estimates for all groups);

TLE=total life expectancy; DLE=disabled life expectancy, percent of remaining life with an activity of daily living disability; CI=95\% confidence interval.

*Indicates statistically significant comparisons $(\mathrm{p}<0.05)$, high unemployment vs. low unemployment. 